\title{
LOGISTICS PROCESSES AND SYSTEMS DESIGN USING COMPUTER SIMULATION
}

In the course of logistics systems designing, great emphasis has been recently put on speed, quality and flexibility of the proposed solutions. The logistics system draft requires then not only an analysis of the logistics systems requirements, a draft of several solution variants and their static verification but also dynamic verification of performance of the designed system in real conditions in a form of computer simulation. The following article deals with the issues of the use of computer simulation for logistics processes and systems designing.

Keywords: Logistics, simulation, design.

\section{Logistics Processes and Systems Designing}

The aim of the logistics processes and systems designing is to draft such a logistics system in the pre-implementation phase which could meet all the necessary technical (optimum use of resources, high level of provided services, system flexibility, high transparency, etc.) as well as economic (return of investments, logistics costs, productivity, etc.) parameters without additional adjustments and interventions into the real system in the phase of its implementation and operation [2 and 3].

The current pressure on fast innovations in the factory means higher demands on logistics systems designing from the point of view of the laboriousness reduction, time and costs consumption for implementation of the entire designing process and increase of quality, complexity and information ability of outputs generated from the process [4].

Due to the above mentioned reasons it is possible to summarize the basic designing process requirements:

- Quick draft of new solutions.

- Observance of the system approaches when designing.

- Designing of logistics systems as a part of the digital factory concept.

- Interactive design of a new logistics system.

- A possibility of a running inspection and evaluation of the proposed solution variants.

- Application of the optimization approaches in the individual stages of the logistics system draft.

- Suitable visualization and presentation of the designing outputs.
- A possibility of dynamic verification of the proposed solution [2].

General procedures of logistics system designing include the following stages (Fig. 1):

1. Preparation, processing and analyzing of the input data.

2. Material flow analysis and transport performances calculation.

3. Analysis of existing means.

4. Processing of the logistics system variants - a static draft of the system.

5. Computer simulation - dynamic dimensioning of the material flow components [2].

\subsection{Preparation, Processing and Analyzing of the Input Data}

The basic information source for the designing is mainly a database from the technical preparation of the production. The data for logistics system designing has to include information about:

- Products (P - Product), which will be manipulated, transported and stored in the logistics system (products types, bills of materials, material consumption standards, construction parameters, physical characteristics of the individual items, etc.).

- Quantities (Q - Quantity), which will be manipulated, transported and stored in the logistics system (overall quantities of transport, time progress of the requirements -

\footnotetext{
* Martin Krajcovic, Andrej Stefanik, Luboslav Dulina

Department of Industrial Engineering, Faculty of Mechanical Engineering, University of Zilina, Slovakia

E-mail: martin.krajcovic@fstroj.uniza.sk
} 


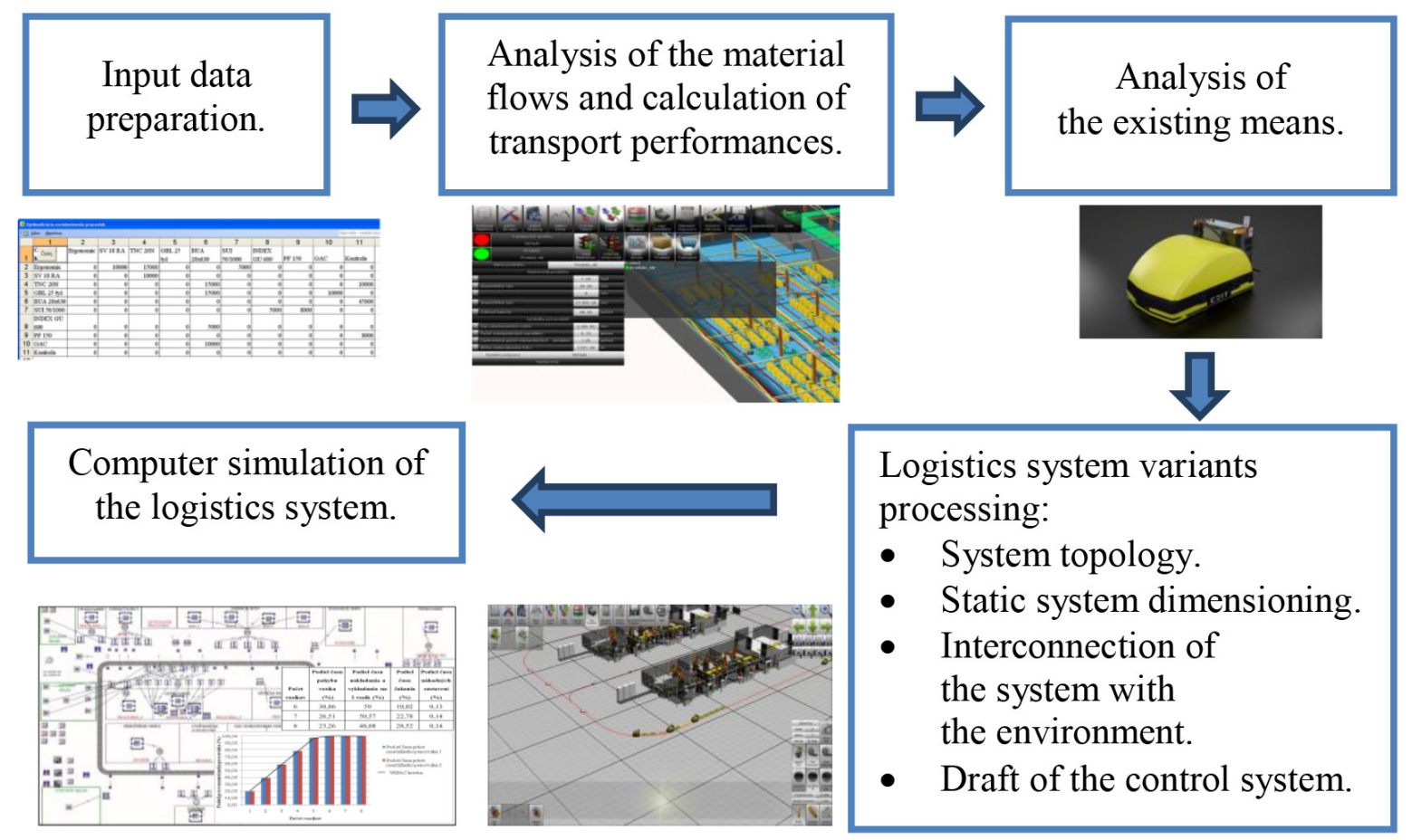

Fig. 1 General procedure of the logistics system designing [2]

seasonality, irregularity, transport, storage and manipulation units, etc.).

- Routings ( $\mathrm{R}$ - Routing) of the individual items in the production and circulation (production procedures, assembly procedures, transportation relations, etc.).

- Supporting services (S - Supporting Services) necessary for the logistics activities implementation (maintenance and modernization of the logistics devices, quality management, packaging, etc.).

- Time ( $\mathrm{T}$ - Time) periods of the individual activities in the logistics processes (loading and unloading time, transport time, preparation times, stock operations time, etc.) [4].

\subsection{Material Flow Analysis and Transport Performances Calculation}

The aim of this stage is a detailed analysis of the input data collected in the previous step and the analysis can provide the information about the current state of the logistics system, requirements for the parameters design and dimensioning of the future logistics system [4 and 5].

The base of the analysis is transported material items and their movements in the logistics or production system [2, 3 and 6].

From the range of products analysis of the transported parts point of view great emphasis is put on the use of tools which enable to analyze all items and to sort them into smaller subgroups (families) for which the common elements or subsystems of logistics system can be designed. The most often used tools are:

- Classification of material items on the basis of construction similarity (shape, dimensions, material, etc.).

- P - Q analysis: classification of the material items on the basis of transported volumes.

- P - P analysis: classification of the material items on the basis of their influence on the overall value flow.

- P - G analysis: classification of the material items on the basis of weight [7].

From the material flows point of view we examine quantitative (intensity of a material flow) and qualitative (movement direction, movement routes) aspect of a material flow. Methods and tools used for the analysis and optimization of the material flow can be divided into the following groups:

- Recording methods: progress lists, a where from - where to table.

- Graphical methods: line scheme, spaghetti diagram, Sankey diagram.

- Optimization methods (analytic, heuristic, metaheuristic): linear and dynamic programming, triangle method, CRAFT, CORELAP, ALDEP, and the like [8].

A synthetic indicator resulting from the analysis of transported parts and their movement is a calculation of transport performances and transport costs:

$p=\sum_{i=1}^{m} \sum_{j=i+1}^{m} f_{i j} * d_{i j}$, 
$z=\sum_{i=1}^{m} \sum_{j=i+1}^{m} f_{i j} * c_{i j} * d_{i j}$

where:

p - an overall transport performance (pcs . $\mathrm{m} /$ time unit),

$\mathrm{z} \quad$ - overall transport costs $(€ /$ time unit),

$f_{i j}$ - intensity of material flows between objects $i$ and $j$ (pcs / time unit),

$c_{i j}$ - transport costs for transport of one material unit per one distance unit between nobjects $i$ and $j(€ /(m$. pcs)),

$d_{i j}$ - distance between objects $i$ and $j(m)$ [8].

\subsection{Analysis of Existing Means}

A part of the analytic stage of logistics system designing is an analysis of available resources. The resources necessary for the logistics process include:

- Transport, manipulation and storage units - they form passive elements of a logistics system, enable effective manipulation, transportation and storage of material items.

- Means of transport and manipulation devices - active parts of the logistics transport system; devices which provide relocation of material from the place of supply to the place of consumption.

- Storage facilities - devices which provide temporary storage of material before it is used.

- Stuff - workers responsible for management and operation of logistic activities.

- Areas - production areas or factory areas, which are connected with the performance of logistics activities [9].

The analysis of existing means provides an assessment of structure, quantity, technical parameters and efficiency of use of the existing means in logistics. In the draft stage the required structure of means is always compared to the existing one and a solution of disproportions between both data files (procurement of missing means, elimination of redundant means) is also a part of the draft. The need for means and the real level of their usage is one of the indicators of productivity and economy assessment of a logistics system [10].

\subsection{Processing of the Logistics System Variants - a Static Draft of the System}

The proposed stage consists in a draft of several variants of the logistics system, which meet the final criteria of the project. Each variant has to deal with:

1. Logistics system topology: the system topology describes the spatial solution of a logistics system, i.e. the arrangements of the individual transport devices, a draft of transport routes, a definition of loading and unloading sites, location of storage facilities, etc. The system topology itself is affected by results of an analysis of the transported range of products and material flows and by the selected suitable methods of transport, manipulation and storage.

2. Static dimensioning of material flow elements: it represents a stage of capacity dimensioning of a logistics system, a selection of specific types of transport, manipulation and storage means and definition of their parameters (bearing capacity, dimensions, speed, loading and unloading time) and a calculation of the overall need of the individual types of devices used in the logistics system is implemented for the proposed topology of a logistics system.

3. Interconnection of the system with the environment: the designed logistics system has to be effectively interconnected to the previous and subsequent factory processes. Due to this fact great emphasis is in the project of a logistics system draft put on the designing of input and output places of the logistics system. The aim is to create such a way of passing and receiving of material items between the system and its environment so that laboriousness and times of waiting for material are reduced.

4. A control system draft: whereas the previous three steps deal with the draft of a part of the logistics system as for the physical material flow, the last step consists of a draft of information flows in the logistics system which includes collection, processing, storing (logistic record keeping) and use of information in the processes of planning and controlling of logistics processing. The control system draft is a key part of the logistics system draft because the organization factors have the greatest influence on the logistics processes progress; the technical parameters are of significantly lower importance [2 and 6].

\subsection{Computer Simulation - Dynamic Dimensioning of the Material Flow Components}

On the basis of the proposed concept of the logistics system it is important to implement the dynamic evaluation of system performance in the final stage of the logistics system project and complete the proposed logistics project in detail. It is possible to implement the analysis from the physical rules and sensors signals point of view (e.g. simulation of the dependency of transport time and changes of speed caused by events on the transport route - an obstacle on the route, loading/unloading of material, reduced speed of a logistics element, etc.) as well as the analysis based on the change of system condition in a form of a discrete or connected event-oriented simulation [10 and 11].

The verification enables not only to define an optimum number of logistics means but also to check the performance 
in emergency situation which can be a malfunction of a part of a production line, a malfunction in the preparation supermarket blocking of the logistics means by an obstacle or verification for how long it is possible to put one or more trucks out of operation because of planned od unplanned maintenance. Compared to the static calculation it provides more relevant information and it is also possible, by means of visualization, to familiarize with the functions of a given system before the implementation itself. It saves not only time but also costs linked with the problem solution in the situation of real production use. Besides standard problem types we encounter the problems related to specific conditions of use in a form of crossroads or cooperation of several types of logistics means. The result is a debugged system, which meets all the necessary requirements with predefined possible critical areas [2 and 9].

In case of need it is possible to check the entire material flow, to find the basic information like running production time, average unfinished production or to define the size of input, output or intermediate operation storage. Considering the use of theoretical classification of likelihood and simulated malfunctions, idle times and changing of production type or consecutiveness of the individual production processes it is possible to gain the real results, which correspond with the performance of the real production system [2 and 9].

\section{Examples of Use of the Computer Simulation in the Logistics System Designing}

A simulation application when solving the problems of logistics system draft will be demonstrated on an example from industrial practice. It concerns a draft and dimensioning of logistics system supply of production workplaces by necessary material inputs.

\subsection{Problem Description}

The production process is implemented in one production hall and the logistics process is ensured through an automated guided vehicle (AGV) system. Material is transported to the individual workplaces in defined sequences from the entrance storehouse. Material is located in box pallets which are transported to the place of need by an AGV towing unit in specialized C-frames (manipulation platforms), see Fig. 2.
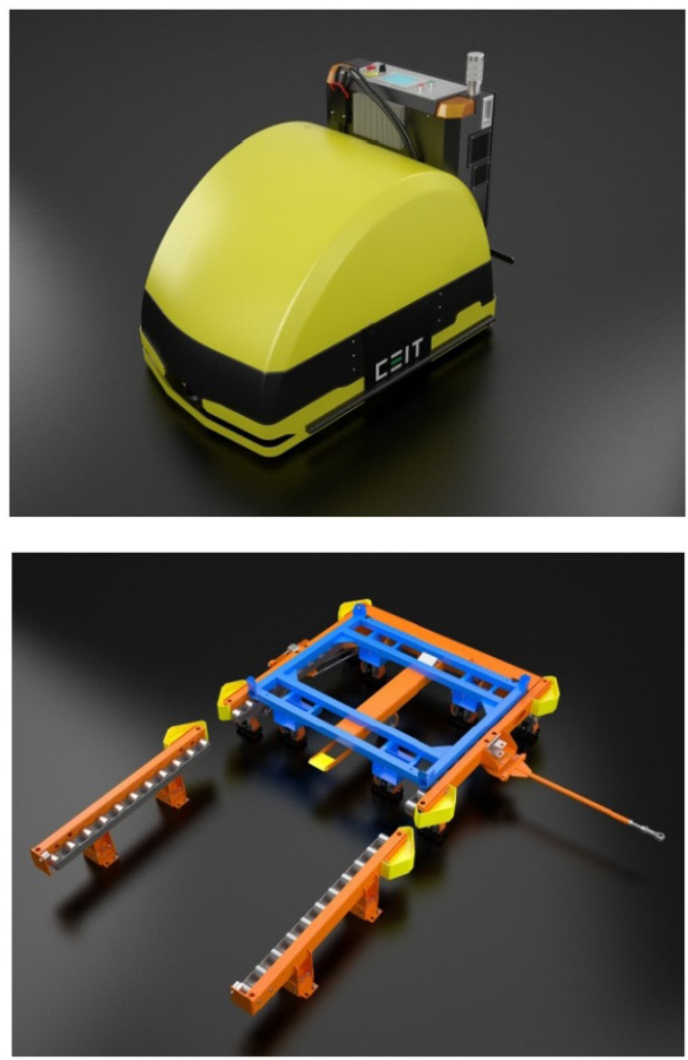

Fig. 2 Transport means used in the logistics system

Material is delivered from the entrance storehouse. There are currently nine catching positions in three time sequences (12 min, $24 \mathrm{~min}, 48 \mathrm{~min}$ ) designed within the storehouse. The sequences are designed on the basis of production cycles of individual workplaces. The arrangement of the catching positions is not optimal at the moment and, therefore, it is necessary, based on the monitored indicators, to define a new arrangement of the sequences in the storehouse.

\subsection{Static Draft of the Logistics System}

There are currently several software solutions for support of the static draft of production and logistics systems like visTABLE from Plavis, Tecnomatix FactoryCAD/FLOW from Siemens or Malaga V3 from Zip Industrieplanung. A software tool CEIT Table was used in the described problem solution due to availability of advanced functions for designing of logistics and transport systems.

The static draft in the environment of CEIT Table software requires the following input data:

- Transported items.

- Volume of transport for the individual items.

- Used manipulation units. 


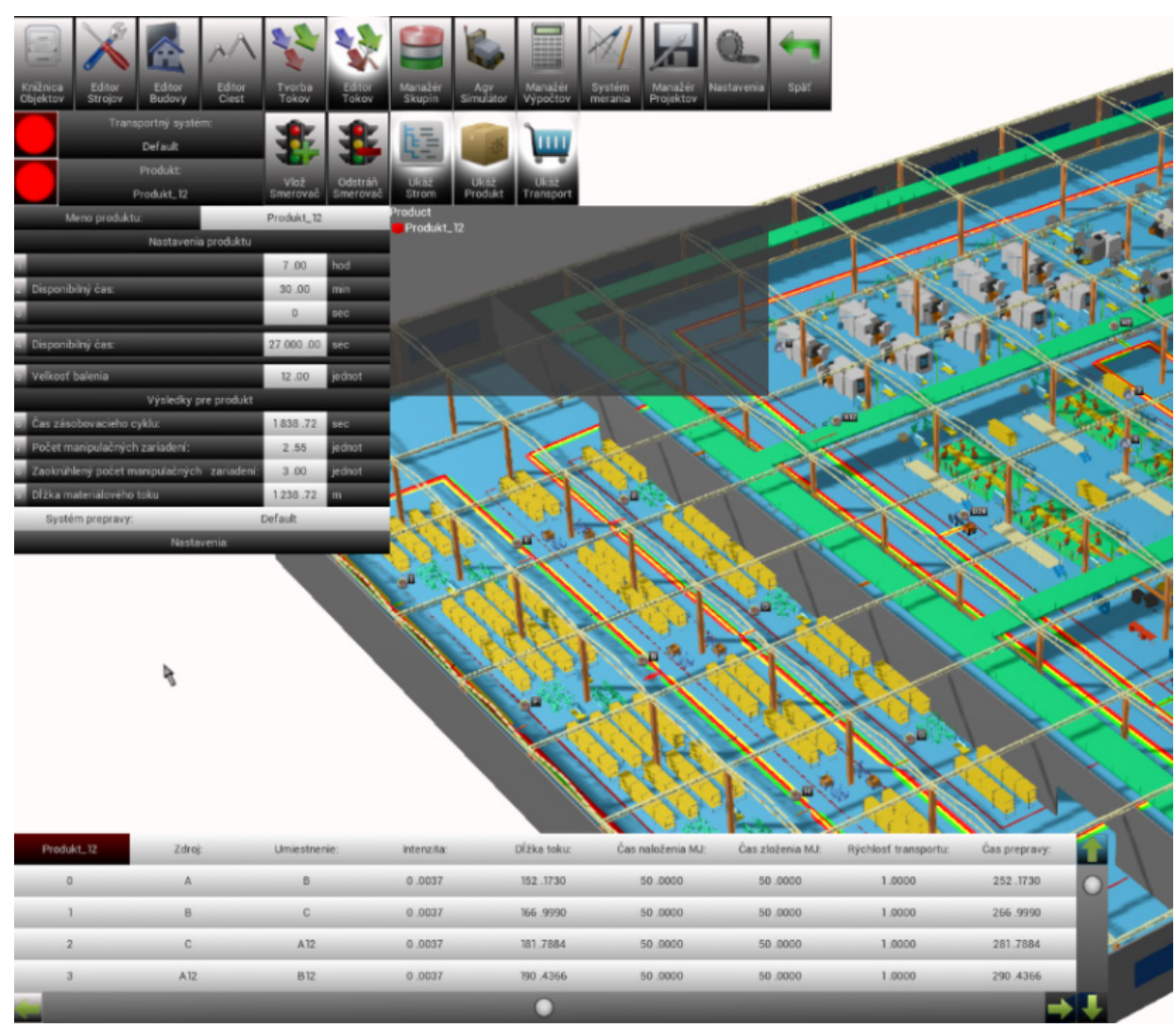

Fig. 3 Example of the transport system draft using the CEIT Table software

- Number of pieces in the manipulation units.

- Available time capacity of a transport device.

- Speed of a transport device.

- Times of loading and unloading.

The CEIT Table system includes graphic environment which enables to design a layout of the logistics system in 3D environment and subsequently on the basis of a 3D model of the layout and entered data to automatically specify the overall laboriousness of transport and the necessary number of transport devices (Fig. 3).

\subsection{Dynamic Simulation of the Designed System}

Dynamic simulation is used for detailed verification of drafts when designing production, assembly and logistics processes. An advantage of the dynamic simulation is modeling and implementation of dynamics into the designed processes and a possibility to examine the influence of mutual interaction of the individual elements of the designed systems. From the logistics system draft and optimization point of view it is primarily applied in the following areas:
- Testing of changes in the transport system and their impact on production/assembly system.

- Testing of various goods supply systems (direct supplying on request, transport circuits and the like) and their assessment.

- Assessment of changes in transport devices types and their capacities on system.

- Testing of changes in priorities of transport tasks and their impact on the system's ability to provide the necessary tasks.

- Monitoring of the influence of crossroads and transport junctions solutions on the utilization of transport devices.

- Testing of impact of the transport devices failure on the material supply.

- Assessment of impact of loading/unloading processes at input/output on the amount of transport devices waiting for loading / unloading.

Storing is also a part of logistics processes, which represents a point of contact of transport and production/ assembly tasks. The simulation is primarily aimed at collection of statistical data and their visualization so it can quickly and simply evaluate various influences on the size related level of storehouses like:

- Influence on planning and different priority rules of tasks on the intermediate operation storehouses. 


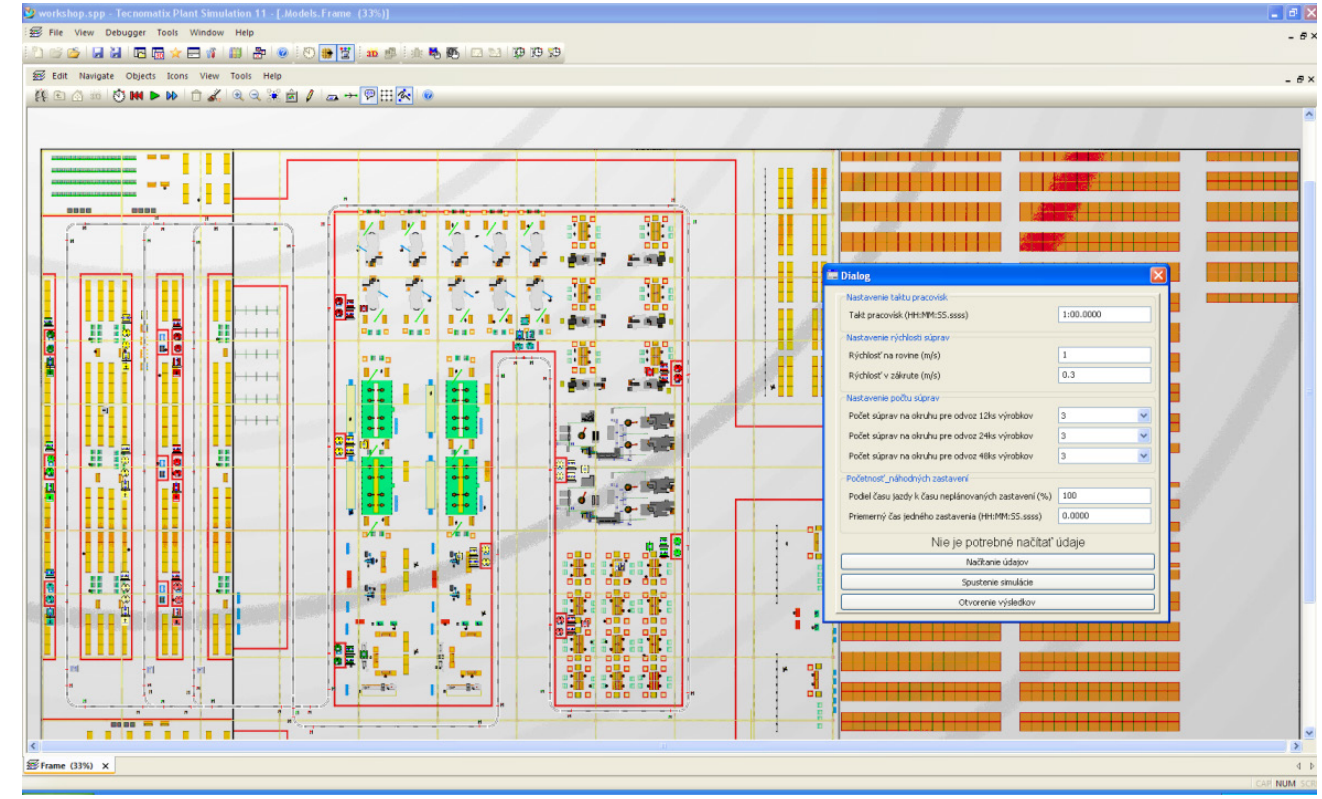

Fig. 4 Simulation model of the logistics system created in the environment of the Plant Simulation software

- Influence of shift pattern in the workplaces in different parts of production/assembly/logistics system on the maximum level of storehouses.

- Influence of random phenomena - breakdowns and type changing - on the overall storehouse capacity, which a factory is forced to create to provide the maximum storehouse utilization.

In the solution of the presented problem a software tool Plant Simulation from SIEMENS was used for the purposes of dynamic simulation. The simulation model of the proposed logistics system is pictured in Fig. 4.

The following input parameters of the model, which can be modified during the implementaion of individual simulation runs, were defined within the testing of the individual variants of workplaces supplying by material items:

- Products processing cycle.

- Vehicle combination speed on flat surface.

- Vehicle combination speed in on bends.

- Number of vehicle combinations on the individual circuits.

- Drive time/accidental stopover time ratio (stopovers due to obstacle on the road).

- Average time of an accidental stopover.

The aim of the simulation is to design and dimension the logistics system in terms of capacity so that it can fulfill the basic function of non-stop supplying of workplaces by means of necessary inputs and at the same time to ensure the optimum utilization of the transport system.

The simulation software Plant Simulation provides both graphic and data outputs when evaluating the individual simulation experiments. A graph of material supply performance in the individual workplaces of a line is pictured in Fig. 5. This parameter was monitored while making a decision about the optimum number of trucks used in the designed transport system.

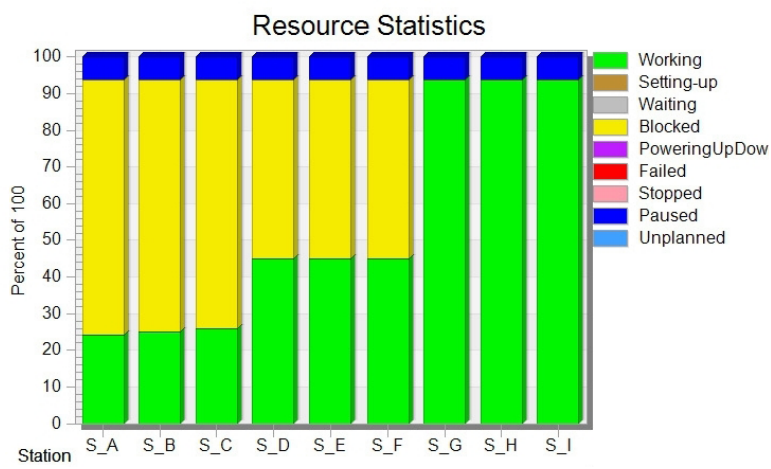

Fig. 5 Graph of material supply performance in the workplaces

Results of the individual simulation experiments are depicted in Table 1 and Fig. 6. The results show that the target criterion was met only in case of simulation experiments number 10 and 22. The remaining results are not satisfying due to unsuitable average utilization of the production system workplaces. The unsatisfactory simulation results were in most of simulation experiments caused by blockage in the first workplace. 
Simulation experiments results

Table 1

\begin{tabular}{|c|c|c|c|c|c|c|c|c|c|c|c|c|c|c|}
\hline \multirow{2}{*}{$\begin{array}{c}\text { Experiment } \\
\text { no. }\end{array}$} & \multicolumn{3}{|c|}{ Tuggers number } & \multicolumn{9}{|c|}{ Utilisaton of workplace } & \multirow[b]{2}{*}{ Satisfy? } & \multirow[b]{2}{*}{ Note } \\
\hline & $\begin{array}{c}\text { sequence }= \\
12 \mathrm{~min}\end{array}$ & $\begin{array}{c}\text { sequence }= \\
24 \mathrm{~min}\end{array}$ & $\begin{array}{c}\text { sequence }= \\
48 \mathrm{~min}\end{array}$ & A & B & c & D & E & $\mathbf{F}$ & G & H & 1 & & \\
\hline 1 & 1 & 1 & 1 & 53.84 & 54.7 & 55.5 & 100 & 100 & 100 & 100 & 100 & 100 & NO & \\
\hline 2 & 1 & 1 & 2 & 28.75 & 28.88 & 29.68 & 53.03 & 55 & 55 & 100 & 100 & 100 & NO & Blocked by first workplace \\
\hline 3 & 1 & 1 & 3 & 13.75 & 13.88 & 14.68 & 21.25 & 21.25 & 21.25 & 100 & 100 & 100 & NO & Blocked by first workplace \\
\hline 4 & 1 & 2 & 1 & 48.75 & 48.97 & 49.77 & 100 & 100 & 100 & 100 & 100 & 100 & NO & \\
\hline 5 & 1 & 2 & 2 & 28.75 & 28.88 & 29.68 & 100 & 100 & 100 & 100 & 100 & 100 & NO & Blocked by first workplace \\
\hline 6 & 1 & 2 & 3 & 13.75 & 13.75 & 13.75 & 36.25 & 36.25 & 36.25 & 100 & 100 & 100 & NO & Blocked by first workplace \\
\hline 7 & 1 & 3 & 1 & 28.75 & 28.92 & 29.73 & 100 & 100 & 100 & 100 & 100 & 100 & NO & \\
\hline 8 & 1 & 3 & 2 & 22.58 & 23.44 & 23.75 & 85 & 85 & 85 & 100 & 100 & 100 & NO & Blocked by first workplace \\
\hline 9 & 1 & 3 & 3 & 14.01 & 14.01 & 14.01 & 52.8 & 51.41 & 52.35 & 100 & 100 & 100 & NO & Blocked by first workplace \\
\hline 10 & 2 & 1 & 1 & 100 & 100 & 100 & 100 & 100 & 100 & 100 & 100 & 100 & YES & \\
\hline 11 & 2 & 1 & 2 & 38.23 & 39.09 & 39.89 & 37.89 & 40 & 39.74 & 100 & 100 & 100 & NO & Blocked by first workplace \\
\hline 12 & 2 & 1 & 3 & 23.75 & 23.88 & 24.68 & 21.25 & 21.25 & 21.25 & 100 & 100 & 100 & NO & Blocked by first workplace \\
\hline 13 & 2 & 2 & 1 & 78.35 & 77.55 & 77.55 & 100 & 100 & 100 & 100 & 100 & 100 & NO & \\
\hline 14 & 2 & 2 & 2 & 28.75 & 29.12 & 29.93 & 52.89 & 55 & 54.74 & 100 & 100 & 100 & NO & Blocked by first workplace \\
\hline 15 & 2 & 2 & 3 & 21.25 & 21.25 & 21.25 & 36.25 & 36.25 & 36.25 & 100 & 100 & 100 & NO & Blocked by first workplace \\
\hline 16 & 2 & 3 & 1 & 53.41 & 52.73 & 52.73 & 100 & 100 & 100 & 100 & 100 & 100 & NO & \\
\hline 17 & 2 & 3 & 2 & 33.75 & 33.75 & 33.75 & 77.89 & 79.71 & 79.71 & 100 & 100 & 100 & NO & Blocked by first workplace \\
\hline 18 & 2 & 3 & 3 & 23.75 & 23.75 & 23.75 & 52.89 & 55 & 54.74 & 100 & 100 & 100 & NO & Blocked by first workplace \\
\hline 19 & 3 & 1 & 1 & 100 & 100 & 100 & 85.12 & 85.25 & 85.12 & 100 & 100 & 100 & NO & \\
\hline 20 & 3 & 1 & 2 & 50.52 & 51.38 & 52.18 & 31.25 & 31.25 & 31.25 & 100 & 100 & 100 & NO & Blocked by first workplace \\
\hline 21 & 3 & 1 & 3 & 30.52 & 31.38 & 32.18 & 21.25 & 21.25 & 21.25 & 100 & 100 & 100 & NO & Blocked by first workplace \\
\hline 22 & 3 & 2 & 1 & 100 & 100 & 100 & 100 & 100 & 100 & 100 & 100 & 100 & YES & \\
\hline 23 & 3 & 2 & 2 & 43.23 & 44.09 & 44.89 & 52.89 & 54.71 & 54.71 & 100 & 100 & 100 & NO & Blocked by first workplace \\
\hline 24 & 3 & 2 & 3 & 28.75 & 28.75 & 28.75 & 36.25 & 36.25 & 36.25 & 100 & 100 & 100 & NO & Blocked by first workplace \\
\hline 25 & 3 & 3 & 1 & 73.91 & 72.38 & 72.38 & 100 & 100 & 100 & 100 & 100 & 100 & NO & \\
\hline 26 & 3 & 3 & 2 & 41.25 & 41.62 & 42.43 & 77.89 & 80 & 79.74 & 100 & 100 & 100 & NO & Blocked by first workplace \\
\hline 27 & 3 & 3 & 3 & 30.52 & 31.38 & 32.18 & 51.25 & 51.25 & 51.25 & 100 & 100 & 100 & NO & Blocked by first workplace \\
\hline
\end{tabular}

where A - I are significations of workplaces

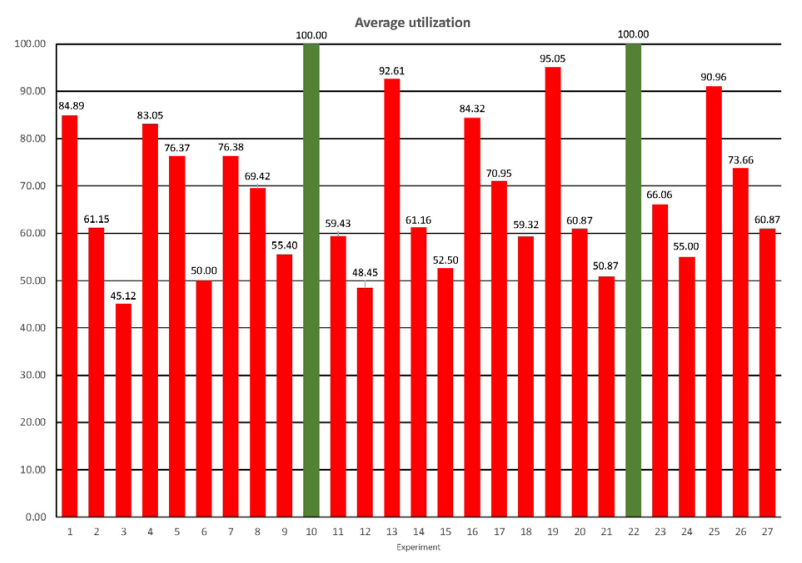

Fig. 6 Average utilization of workplaces achieved in the individual simulation experiments

\section{Conclusion}

Computer simulation currently represents an important designing and optimization tool of logistics processes and systems. Its main advantage lies in a possibility, in case of a correct construction of a simulation model and after its verification and validation, to simulate with a very high accuracy the behavior of a logistics system in real conditions. The individual simulation experiments are used for modeling of various situations and scenarios, which can occur in reality and enable to assess their impact on achievement of target indicators of the designed system. Computer simulation is, therefore, a very important tool when implementing "what-if" analyses, which are a part and parcel of the conceptual and detailed designing of production, assembly and logistics systems. This is the reason why computer simulation currently forms an integral part of digital factory and PLM (Product Lifecycle Management) concept of software solutions.

\section{References}

[1] HNAT, J.: Virtual Factory Framework. Industrial Engineering Moves the World - InvEnt 2012, University of Zilina, 2012, 56-59, ISBN 978-80-554-0542-1.

[2] KRAJCOVIC, M. et al.: Intelligent Manufacturing Systems in Concept of Digital Factory. Communications - Scientific Letters of the University of Zilina, vol. 15, No. 2, 2013, Zilina, 77-87, ISSN 1335-4205.

[3] MICIETA, B, BINASOVA, V., HALUSKA, M.: The Approaches of Advanced Industrial Engineering in Next Generation Manufacturing Systems. Communications - Scientific Letters of the University of Zilina, vol. 16, No. 3A, 2014, Zilina, pp. 101-105, ISSN 1335-4205 


\section{COMMNICOIIONS}

[4] LI, J., MEERKOV, S. M.: Production Systems Engineering. New York: Springer, 2009, 666 p., ISBN 0387755780

[5] ALTUNTAS, S., SELIM, H.: Facility Layout using Weighted Association Rule-based Data Mining Algorithms: Evaluation with Simulation. Expert Systems with Applications, 39 (1), 2012, pp. 3-13.

[6] PLINTA, D., WIĘCEK, D.: Production Systems Design. Wydawnictwo Naukowe Akademii Techniczno-Humanistycznej, BielskoBiala, 2012, p. 122, ISBN 978-83-63713-06-5

[7] JERBI, A. et al.: Functional vs Cellular Layout: Using Simulation as a Comparison Tool. $3^{\text {rd }}$ intern. conference on advances in mechanical engineering and mechanics, 2006.

[8] GREASLEY, A.: Using Simulation for Facility Design: A Case Study. Simulation Modelling Practice and Theory, 16 (6), 2008 , pp. 670-677.

[9] EBBESMEYER, P. et al.: Designing Flexible Production Systems with Virtual Reality. Proc. of the ASME 2001 Design Engineering Technical Conference on Computers and Information, Pittsburgh, 2001

[10] HOVANEC, M, SINAY, J., PACAYOVA, H.: Application of Proactive Ergonomics Utilizing Digital Plant Methods Based on Augmented Reality as a Tool Improving Prevention for Employees. Intern. Symposium on Occupational Safety and Hygiene: 02. 2014: Guimares, pp. 182-185, Guimares: SPOSHO, 2014, ISBN 978-989-98203-2-6.

[11] GASOVA, M.: Modern Methods in Ergonomics Research and European Legislation. Advanced Industrial Engineering. Monograph. Publisher: Wydawnictwo Fundacji Centrum Nowych Technologii : Bielsko Biala, 2015, 1t ed., pp. 147-164, ISNB 978-83-927531-7-9. 